\title{
A Study of the Intercourse between Zhang Yu and Yu Ji---the Calligrapher in Yuan Dynasty
}

\author{
Yang Song \\ Jilin University of the Arts, Changchun, Jilin, China
}

\begin{abstract}
In the Yuan Dynasty, the minority nationalities was entered the Central Plain for the first time in Chinese history. During this period, although the status of Chinese people and intellectuals was low, their ideological control was loose, thus forming a unique literary style. The rapid promotion of the status of the humanities such as painting, calligraphy and literature in the life of the scholars brought about a brand-new attitude towards life, especially in the late Yuan Dynasty, the humanities taste and the artistic orientation showed many new changes. And the development of literature, calligraphy and painting in the Song Dynasty, as well as the establishment of the regime in the Yuan Dynasty all accelerated this process. Facing the setbacks brought by the Mongolian yuan rule, some intellectuals turned to create an atmosphere through some group activities of calligraphy and painting, and literature and art were also given a higher status. As a famous calligrapher in the middle and late Yuan Dynasty, Zhang Yu was an influential Taoist and poet. On the basis of studying Zhang Yu's calligraphy art, this paper analyzes his social intercourse and its influence on his calligraphy thoughts and artistic style. Especially in calligraphy, he was first taught by Zhao Mengfu, and then learned from Huaisu and Zhang $\mathrm{Xu}$, forming a handsome and free style. In addition, he made many friends all his life. After becoming a monk, he traveled to famous mountains in the south of the Yangtze River and made friends with famous people. Therefore, studying the intercourse between Zhang $\mathrm{Yu}$ and yu Ji can restore the real situation of the Literati's communication at that time, understand Zhang Yu's multiple accomplishments of Taoism, poet and calligrapher, and the relationship between them. It can also learn his experience in calligraphy, the internal and external causes of his calligraphy style, and the influence and function of Mingxi Literati's elegant and Yuji's intercourse on the formation of his artistic style.
\end{abstract}

Key words: Yuan Dynasty; Zhang Yu; cultural environment

\section{Introduction}

In General, Zhang Yu inherited the calligraphy of the Jin and Tang dynasties and studied the calligraphy of the Song Dynasty. Therefore, he did not go beyond the scope of the retro style proposed by Zhao. In the second year of Emperor Qing, Zhang Yu joined the imperial court in Beijing with Wang Shouyan. At that time, Zhang Yu was only 30s, but Yu Ji was in his 40s. Zhang Yu regarded $\mathrm{Yu} J \mathrm{~J}$ as teacher and friend. As one of the "four outstanding scholars" in the Yuan Dynasty, Yu Ji was a master of learning and literature, and was well versed in the philosophy of Zhu Xi. They two had a great influence on future generations. As an official in the capital, Yu Ji's poems and essays showed the distinctive characteristics of pavilion style, advocating Confucianism and extolling the political purity and brightness. Therefore, most of the important documents of the court at that time came from his thought, leaving a lot of famous poems and essays.

Copyright (C) 2021 by author(s) and Frontier Scientific Research Publishing Inc.

This work is licensed under the Creative Commons Attribution International License (CC BY 4.0).

$\mathrm{http} / / /$ creativecommons.org/licenses/by/4.0/ 
$\mathrm{Yu} \mathrm{Ji}$ is not only famous for his poems and writings, but also for his elegant and beautiful calligraphy inherited from Zhao Mengfu, a famous calligrapher in the Yuan Dynasty. Zhang Yu once wrote a letter asking Yu Ji to write an epitaph for Ni Zan, a brother of his good friend, which shows that Zhang Yu and Yu Ji have a direct relationship.

Zhang Yu visited Maoshan Mountain twice in his life. In 1312, he ascended to Maoshan under the guidance of Zhou Dajing, but he had not yet intersected with $\mathrm{Yu}$ Ji at that time. In the summer of 1322, on his way from his hometown of Chongren to the Tomb of Wuzhong Province, Yu Ji passed through Hangzhou, Zhejiang Province. And they probably met in Hangzhou then. At that time, Zhang Yu was on his way to Maoshan Mountain. In the poem, Zhang Yu, who was about to set out, was standing alone on the boat. The breeze was blowing slowly, and his clothes fluttered. The poem was full of fairy spirit, showing his outstanding behavior like that of immortals. "This is the time when you remember each other the most." This sentence is true and sincere. At the moment, they no longer have the estrangement of the first acquaintance.

Although Zhang Yu was born in the Taoist school, he has left behind a large number of poems and prose handed down from generation to generation. He was also a representative of history-telling poems in the Yuan Dynasty. In addition to having a Taoist family background and a high-ranking official in the Orthodox Church, Zhang Yu also stood out among many poets, and was appreciated by the majority.

\section{2. the Taoist Sentiments and Poetic Temperament of Zhang $\mathrm{Yu}$ and $\mathrm{Yu} \mathrm{Ji}$}

According to historical records, Zhang Yu's ancestors had the status of Taoist priests, and had contacts with many Taoist masters. It may be because they believe in Taoism at home, and the people who come to the home are all sage-like type, he has been influenced by the quiet and inactive Taoism since he was a child. The prosperity of Taoism and the reclusive style of writing in the Yuan Dynasty had created his lofty and aloof character. After entering the Maoshan Taoist school, he became obsessed with Taoism. Zhang Yu spent 40 years in it, specialized in ballistics. Zhang's Taoist cultivation influenced his artistic style ideologically. And his early clean and bright calligraphy style is related to the thought of "naturalness" and "non-action" in Taoist paintings works, like a natural breeze, which feels pure and not vulgar.

The influence of the demise of the Southern Song Dynasty on literati thought was not a simple Dynasty change. The Mongol rulers, who conquered the world by force, had a strong tendency to slavery, which caused many scholars lose the opportunity to learn, which was sad and helpless. The south of the Yangtze River has been a place where the literati gathered since ancient times, but the rule of the Yuan Dynasty made the literati unable to be official or of no use. Therefore, it can be seen that Zhang Yu became a Taoist priest for the influence of the overall environment of society. Moreover, Zhang $\mathrm{Yu}$ was knowledgeable, being an official and doing business were not what he pursued. His own Literary achievement made him concentrate on Tao and pursue a higher realm of life. Zheng Sixiao once said, "when I was young I was a scholar; by middle age, I have ventured into the realm of immortals; in the twilight years, I have travelled in the realm of Zen.Buddhism." With these information on social conditions, we can understand the life of Zhang Yu as a confucian and a Taoist.

The Yuan Dynasty was a special period in the history of our country. Foreign invasion, the impact of the Han culture, the vigorous promotion of the handicraft industry, the improvement of the status of the merchants, the expansion of the city scale, and the policies pursued by the Mongol rulers put the literati in an unfortunate situation. Religious monks enjoyed the privilege, and the field of thought was active and loose. Especially when Taoism was developing and prospering, the literati chose to retreat or seek Tao had become a cultural phenomenon. For nearly ten years, Zhang Yu lived in seclusion in Maoshan Mountain, aspiring to make a difference in Taoism. Because of his achievements in monasticism, calligraphy and painting, he got acquainted with Zhao Mengfu, Yuji, Yang Weizhen and others. 


\section{The Influence of the Intercourse between Zhang $\mathrm{Yu}$ and $\mathrm{Yu}$ Ji on the Formation and Evolution of His Calligraphic Thoughts}

Zhang Yu's Taoist sentiment and poet's temperament are reflected in his calligraphy works. His taoist practice has influenced his calligraphy style from ideological aspects. His early clean and bright calligraphy style is incorporated Taoist inaction thought into calligraphy works, with a sense of pure and no vulgarity. Zhang Yu traveled all over the famous mountains in Jiangsu and Zhejiang, during which he met many famous calligraphers. Yu Ji, a famous scholar and Taoist, had a great influence on Zhang Yu's Taoism and academics. It also made the young Zhang Yu feel that his talent and learning is shallow, and realizing that the only way to learn is to be humble and eager.

Later, Zhang Yu came to Beijing with the Taoist Master Wang Shouyan, and met with Yu Ji. It should be said that the interaction with Yu Ji greatly broadened Zhang Yu's cultural circle, enabling him to exchange ideas with the literati and scholars in the capital, which located in the political center of the country. The scene of the intersection of political culture influenced Zhang Yu to a certain extent. His style at that time belonged to the realistic Eastern Orthodox ancient calligraphy style, which was more imitated and learned from the predecessors, but not yet come out of the shadow of others. But most of times Zhang Yu was still active in the cultural circle of the capital as a Taoist.

\section{Conclusions}

As a famous poet, Taoist priest and calligrapher in Yuan Dynasty, Zhang Yu received a good education in culture and calligraphy. And as one of the "four outstanding scholars" in Yuan Dynasty, Yu Ji was well-known as one of the most famous poets, good at poetry and song. Wenduo advocated Confucian tradition and neo-confucianism, and eulogized Yuanshi. Their friendship had a profound influence on Zhang Yu. It was also Zhang Yu's extraordinary achievements in Taoism that enabled him to enter the capital and travel to the south of the Yangtze River so that he could get to know Yuji and others. The group characteristics of the literati in the Yuan Dynasty are very obvious. They had a fine collection of calligraphy and painting, singing and playing, and influence each other in their poetic ideas and styles. Zhang Yu's frequent participation in Yushan collection and other cultural activities in calligraphy and painting made his poetic and calligraphic style surpass the limit of the Taoist's style and had a certain influence and status among the literati of the Yuan Dynasty, making him a famous poet and calligrapher. Zhang Yu is also a microcosm of the calligraphers group in the middle and late Yuan Dynasty. Calligraphers not only raised their literary status and social fame by communicating with the literati, expressing their friendship and ideals, but also had the important influence to own artistic style and thought. Zhang $\mathrm{Yu}$ almost had the experience of making friends with the famous poets and calligraphers during the middle and late Yuan Dynasty, covering the north and south regions, including officials, scholars, poets and other people of all kinds, thus making the style of calligraphy and poetry change. It can be said that Zhang $\mathrm{Yu}$ and $\mathrm{Yu} \mathrm{Ji}$ are the epitome of the life situation of the literati calligraphers in the Yuan Dynasty.

\section{Conflicts of Interest}

The author declares no conflicts of interest regarding the publication of this paper.

\section{References}

[1] Zhang Y. (2003). Synopsis of a Collection of Unofficial Histories. Summary of Complete Collection of Four Treasuries General Catalogue 168. Zhonghua Book Company.

[2] Ding X.Y. (2005). Zhang Yu Chronicle. Master's thesis at Guangxi Normal University.

[3] Yao S.Y. (1993). The Mentality of the Literati in Yuan Dynasty. Arts and Culture Publishing House.

[4] Zheng X.S.(1991). Zheng Xiao Si Collection. Shanghai Ancient Books Publishing House. 